\title{
Streptomyces sp. strain MUSC 5 from mangrove forest in Malaysia: Identification, antioxidant potential and chemical profiling of its methanolic extract
}

Hefa Mangzira Kemung ${ }^{1,2}$, Loh Teng-Hern Tan², Kok-Gan Chan ${ }^{3,4 *}$, Hooi-Leng Ser ${ }^{2}$, Jodi Woan-Fei Law $^{2}$, Bey-Hing Goh ${ }^{1,5,6 *}$

${ }^{1}$ Biofunctional Molecule Exploratory Research Group (BMEX), School of Pharmacy, Monash University Malaysia, 47500 Bandar Sunway, Selangor Darul Ehsan, Malaysia

${ }^{2}$ Novel Bacteria and Drug Discovery Research Group (NBDD), Microbiome and Bioresource Research Strength, Jeffrey Cheah School of Medicine and Health Sciences, Monash University Malaysia, 47500 Bandar Sunway, Selangor Darul Ehsan, Malaysia

${ }^{3}$ Division of Genetics and Molecular Biology, Institute of Biological Sciences, Faculty of Science, University of Malaya, 50603 Kuala Lumpur, Malaysia

${ }^{4}$ International Genome Centre, Jiangsu University, Zhenjiang 212013, PR China

${ }^{5}$ College of Pharmaceutical Sciences, Zhejiang University, 866 Yuhangtang Road, Hangzhou 310058, China

${ }^{6}$ Health and Well-being Cluster, Global Asia in the 21st Century (GA21) Platform, Monash University Malaysia, Bandar Sunway 47500, Malaysia.

\begin{abstract}
The present study explored the antioxidant potential of a Streptomyces sp. strain MUSC 5 from the mangrove forest soil in the Pahang State, Peninsular of Malaysia and determined the presence of biologically active chemical constituents contained in the methanolic extract. The 16S rRNA genomic DNA extraction, phylogenetic analysis and phenotyping methods were used to confirm identity of strain. The antioxidant potential of methanolic extract from Streptomyces sp. strain MUSC 5 was assessed using a number of antioxidants assays which included free radical scavenging assays, metal chelation and ferric reduction antioxidant power (FRAP) assay. Furthermore, Gas chromatography-Mass Spectrometry (GC-MS) was used to determine the presence of biologically active chemical compounds in methanolic extract of Streptomyces sp. strain MUSC 5. The strain was confirmed as belonging to Streptomyces genus. Antioxidant studies of the methanolic extract from Streptomyces sp. strain MUSC 5 revealed antioxidant activity of $24.97 \pm 0.99 \%, 22.95 \pm 3.21 \%$ and $26.81 \pm 1.05 \%$ against free radicals ABTS, DPPH and metal chelation, respectively. The result of FRAP assay was expressed in dose of 1-2 mg which was equivalent to 1.73- 2.15 microgram $(\mu \mathrm{g})$ of ascorbic acid. GC-MS analysis carried out on the methanolic extract of Streptomyces sp. strain MUSC 5 detected the presence of 11 known compounds belonging to pyrrolopyrazine, esters, fatty acid esters, triterpene and an alkane group of compounds. The study supports the notion that Streptomyces from underexplored mangrove forest offer promising Streptomyces with antioxidant activity and could serve as important sources for new antioxidant agents.
\end{abstract}

Keywords: Streptomyces; Antioxidative; Mangrove; Radical scavenging

Received: $18^{\text {th }}$ April 2020

Accepted: $20^{\text {th }}$ May 2020

Published Online: $28^{\text {th }}$ May 2020

*Correspondence: Kok Gan Chan, Institute of Biological Sciences, Faculty of Science, University of Malaya, 50603 Kuala Lumpur, Malaysia. kokgan@um.edu.my; Bey-Hing Goh, School of Pharmacy, Monash University Malaysia, 47500 Bandar Sunway, Selangor Darul Ehsan, Malaysia. goh.bey.hing@monash.edu

Citation: Kemung HM, Tan LT-H, Chan K-G, et al. Streptomyces sp. strain MUSC 5 from mangrove forest in Malaysia: Identification, antioxidant potential and chemical profiling of its methanolic extract. Prog Microbes Mol Biol 2020; 3(1): a0000087. https://doi.org/10.3687/pmmb.a0000087

\section{Introduction}

Oxidative stress is a pathological condition caused by presence of high levels of reactive oxygen species (ROS) with an insufficient amount of defensive antioxidants in the body originating from mitochondria, in some instances, can be acquired as air pollutant such as carbon monoxide ${ }^{[1]}$. To date, there is growing evidence linking oxidative stress caused by mitochondrial dysfunction with the progression of degenerative diseases in the 
adult population ${ }^{[2]}$. The role of antioxidant is to supply the body with optimal antioxidants, thereby reducing unwanted effects of circulating ROS. Previously, a study that investigated natural antioxidants as dietary supplements was shown to be effective in regressing cancer $^{[3]}$. Over the years, microbes have risen on the stage of prominence as producers of useful drugs against debilitating diseases ${ }^{[4-10]}$.

The bacteria genus of Streptomyces is characterized as a gram-positive, filamentous, soil-dwelling and saprophytic in nature ${ }^{[11,12]}$. The soil consists of a diverse microbial community which includes bacteria such as Streptomyces ${ }^{[13]}$ and competition for nutrients can be extremely intense ${ }^{[14]}$. Nevertheless, Streptomyces adapted well to the surrounding environment and this may be justified by the fact that they carry a large genome size with high $\mathrm{G}-\mathrm{C}$ content ${ }^{[15-21]}$ that enable the production of vast array of enzymes, proteins and secondary metabolites to process variety of materials needed for growth and survival ${ }^{[22-26]}$. The genus of Streptomyces under the Actinobacteria phylum are by far the most recognized producers of current drugs and secondary metabolites with diverse biological activities ${ }^{[4,27-31]}$. There is renewed interest in the Streptomyces strains and species lurking in understudied ecological niches and awaiting discoveries which can aid development of new and needed drugs ${ }^{[32-34]}$. Additionally, there is growing evidence suggesting Streptomyces from the understudied mangrove habitat as potential sources of antioxidants in the pharmaceutical industries ${ }^{[35-50]}$.

The mangrove forest is a unique ecosystem which consists of stretch of forests at the confluence of land and the marine ecosystems. Concentrated mostly in 15 countries with an estimated coverage of $75 \%$ of their coastline margin ${ }^{[51]}$, mangrove forests are home to a rich microbial community ${ }^{[52]}$ which remain relatively understudied for their biologically active properties ${ }^{[3-56]}$. Herein, we report a Streptomyces sp. strain MUSC 5 with antioxidant potential that was previously isolated from the soil in the mangrove forest of Malaysia. In addition, GCMS analysis detected 11 known compounds present in the methanolic extract of Streptomyces sp. strain MUSC 5. Overall, this study supports the notion of mangrove forest in Malaysia harbouring promising Streptomyces that have yet to be investigated for important biologically active compounds.

\section{Materials and Methods}

\section{Sampling and maintenance of Streptomyces sp. strain MUSC 5}

The soil sample for the present study, was collected from mangrove forest in Tanjung Lumpur, Malaysia (MUSCTLS4 3०48'21.3” N 103'20'3.3”E) in December $2012^{[43,57,58]}$. Soil sample collected consisted of portion of the soil layer just beneath $2-3 \mathrm{~mm}$ of the surface with a depth up to $30 \mathrm{~cm}$ and was achieved by a sterile trowel. Soil samples were aseptically packed into a plastic bag and delivered safely to be stored at $-20^{\circ} \mathrm{C}$ prior to air drying. Air-dried samples were then ground and processed by wet heat sterilization. Pre-treated sample was suspended in previously autoclaved water, diluted and plated uniformly across ISP 2 media supplemented with antifungal drugs which selectively promoted growth of Streptomyces. Growth was monitored by continuous subculture onto freshly made ISP 2 media until pure isolates was achieved. Pure isolates were then kept on ISP2 agar slant and $20 \%$ glycerol at $-20{ }^{\circ} \mathrm{C}$ as stocks for future work.

\section{Phylogenetic analysis of Streptomyces sp. strain MUSC 5}

The isolation of genomic DNA (gDNA) was for the purpose of amplifying the $16 \mathrm{~S}$ rRNA region in the genome ${ }^{[59,60]}$. The sequenced 16S rRNA gene of Streptomyces sp. strain MUSC 5 was then entered into GenBank/ EMBL/ DDBJ database to retrieve member type strains with the closest match. Multiple alignment for all the member type strains retrieved from GenBank/EMBL/DDBJ database was achieved using CLUSTAL-X software ${ }^{[61]}$. The stability of the generated phylogenetic tree was verified by following Felsenstein method ${ }^{[66]}$.

\section{Phenotypic characterization of Streptomyces sp. strain MUSC 5}

Phenotypic characterization of Streptomyces sp. strain MUSC 5 consisted of growth characteristics, physiological tolerance levels and production of extracellular enzymes. Growth characteristics of Streptomyces sp. strain MUSC 5 cultured at $28{ }^{\circ} \mathrm{C}$ for $7-14$ days, was visually inspected on conventional nutrient media - International Streptomyces Project (ISP) 2, ISP3, ISP4, ISP5, ISP6, ISP7 ${ }^{[67]}$, Streptomyces agar (SA) ${ }^{[68]}$, Nutrient agar (NA) ${ }^{[69]}$, Actinomycete isolation agar (AIA) ${ }^{[70]}$ and starch casein agar (SCA) ${ }^{[71]}$. Soluble pigment and colony colour on each growth media were monitored ${ }^{[72]}$. Physiological tolerance assessment of Streptomyces sp. strain MUSC 5 was evaluated by growing at temperature range of $4-50{ }^{\circ} \mathrm{C}$, salinity levels of $0-10 \% \mathrm{w} / \mathrm{v}$ and $\mathrm{pH} 2-10$. Biochemical properties of Streptomyces sp. strain MUSC 5 evaluated the production of extracellular enzymes. Presence of catalase was investigated by observing bubble formation following the dropping of $3 \%(\mathrm{v} / \mathrm{v})$ hydrogen peroxide onto a culture of Streptomyces sp. MUSC $5^{[73]}$. Test to detect hemolysis activity was carried out on a 5-day old culture grown on blood agar media ${ }^{[74]}$. Production of extracellular enzymes were determined on ISP 2 media $^{[75]}$.

\section{Fermentation process and extract preparation}

A 10-day culture of Streptomyces sp. strain MUSC 5 in 10 $\mathrm{mL}$ of Tryptone Soya Broth (TSB) media and afterwards inoculated in $200 \mathrm{~mL}$ sterile Han's Fermentation Media 1 (Biomerge, Malaysia) shaken in incubator at $28{ }^{\circ} \mathrm{C}, 220$ rpm for 10 days. Secondary metabolites in supernatant was collected by initial centrifuging followed by filtration and freeze-drying ${ }^{[60]}$. Extraction of secondary metabolites from freeze-dried supernatant was performed using organic solvent methanol. Crude methanolic extract was collected after evaporation of methanol using of rotary evaporator and stored conveniently at $-20{ }^{\circ} \mathrm{C}$ for future use ${ }^{[43]}$.

\section{Antioxidant assays}

Scavenging of ABTS radical 
Scavenging of 2,2'-azino-bis(3-ethylbenzothiazoline6-sulfonic acid) (ABTS) radical by the methanolic extract was examined according to Tan et al. (2017) ${ }^{[41]}$. In short, ABTS radical $\left(\mathrm{ABTS}^{\bullet^{+}}\right)$was obtained from the reaction of $7 \mathrm{mM}$ of ABTS with $2.45 \mathrm{mM}$ of potassium persulfate $\left(\mathrm{K}_{2} \mathrm{~S}_{2} \mathrm{O}_{8}\right)$. The six concentrations $(0.125 \mathrm{mg} / \mathrm{mL}, 0.25 \mathrm{mg} / \mathrm{mL}, 0.5 \mathrm{mg} / \mathrm{mL}, 1 \mathrm{mg} / \mathrm{mL}$, $2 \mathrm{mg} / \mathrm{mL}$ and $4 \mathrm{mg} / \mathrm{mL}$ ) of methanolic extract were prepared by 2 -fold dilution in 96 - well plate. The ABTS radical was then introduced into the 96 well plate. The plate was then kept in dark for 20 minutes prior to reading of the UV absorbance at $734 \mathrm{~nm}$. Gallic acid served as the standard for this experiment. The following formula was used to calculate the radical scavenging activity of methanolic extract in percentage $(\%)$ :

$$
\% \text { ABTS scavenging activity }=\frac{\begin{array}{l}
\text { Absorbance of control }- \\
\text { absorbance of sample }
\end{array}}{\text { Absorbance of control }} \times 100 \%
$$

\section{Scavenging of DPPH radical}

Scavenging of 2, 2-diphenyl-1-picrylhydrazyl (DPPH) radical by the methanolic extract was performed according to Tan et al. $(2017)^{[41]}$. The test was run in a 96-well microplate. A series of concentration of methanolic extract was prepared in the 96 -well plate by 2 -fold dilution ranging from $0.125 \mathrm{mg} / \mathrm{mL}, 0.25 \mathrm{mg} / \mathrm{mL}, 0.5 \mathrm{mg} / \mathrm{mL}, 1 \mathrm{mg} / \mathrm{mL}$, $2 \mathrm{mg} / \mathrm{mL}$ and $4 \mathrm{mg} / \mathrm{mL}$. A solution of DPPH ethanol $(0.016 \% \mathrm{w} / \mathrm{v})$ was then added into 96 well plates containing the methanolic extract and left standing in the dark for 20 minutes at room temperature. The UV absorbance of the mixture was read at a wavelength of $515 \mathrm{~nm}$. Gallic acid was used as the control for this test. The following formula was used to calculate the radical scavenging activity of methanolic extract in percentage $(\%)$ :

$$
\% \text { DPPH radical scavenging activity }=\frac{\begin{array}{l}
\text { Absorbance of control - } \\
\text { absorbance of sample }
\end{array}}{\text { Absorbance of control }} \times 100 \%
$$

\section{Chelation of metal ions}

The metal chelating assay was assessed according to Adjimani and Asare ${ }^{[76]}$ and performed in a 96 well plate. Methanolic extract were prepared in the concentration of $0.125 \mathrm{mg} / \mathrm{mL}, 0.25 \mathrm{mg} / \mathrm{mL}, 0.5 \mathrm{mg} /$ $\mathrm{mL}, 1 \mathrm{mg} / \mathrm{mL}, 2 \mathrm{mg} / \mathrm{mL}$ and $4 \mathrm{mg} / \mathrm{mL}$ and placed in individual wells. A $2 \mathrm{mM}$ ferrous sulfate $\left(\mathrm{FeSO}_{4}\right)$ was afterwards added into the wells followed by the addition of $5 \mathrm{mM}$ ferrozine. In this reaction mixture, both methanolic extract and ferrozine compete with each other for ferrous ion. Ethylenediaminetetraacetic acid (EDTA) was the standard used in this experiment. The following formula was used to calculate the metal chelating activity of methanolic extract in percentage (\%):

\footnotetext{
Absorbance of control -

$\%$ Metal chelating activity $=\frac{\text { absorbance of sample }}{\text { Absorbance of control }} \times 100 \%$
}

\section{Ferric reduction antioxidant power (FRAP) assay}

Reduction of ferric ion was evaluated according to Adjimani and Asare ${ }^{[76]}$ with few alterations made. Series of concentration of methanolic extract ranging from $5 \mathrm{mg} /$ $\mathrm{mL}, 10 \mathrm{mg} / \mathrm{mL}, 20 \mathrm{mg} / \mathrm{mL}, 40 \mathrm{mg} / \mathrm{mL}$ and $80 \mathrm{mg} / \mathrm{mL}$, were prepared in $25 \mu \mathrm{L}$ in a $1.5 \mathrm{~mL}$ microcentrifuge tubes. A 25 $\mu \mathrm{L}$ from phosphate buffer $(0.2 \mathrm{M})$ and $25 \mu \mathrm{L}$ from potassium ferricyanide $(1 \%)$ were subsequently added into sterile 1.5 $\mathrm{mL}$. The reaction mixtures were then heated to $50{ }^{\circ} \mathrm{C}$ and temperature kept constant for 20 minutes before cooling down to room temperature. A $25 \mu \mathrm{L}$ of $10 \%$ trichloroacetic acid (TCA) was afterwards added to cease the reaction. An $80 \mu \mathrm{L}$ was transferred to wells in 96 well plate with a further addition of $20 \mu \mathrm{L}$ of ferric chloride $\left(\mathrm{FeCl}_{3}\right)$. The UV absorbance reading was taken at wavelength of $700 \mathrm{~nm}$ and results expressed in equivalent dose of ascorbic acid.

\section{Detection of compounds in methanolic extract with GC-MS}

Profiling of individual constituents in the methanolic extract was achieved by using Agilent Technologies $6980 \mathrm{~N}$ with a 5979 Mass Selective Detector ${ }^{[42]}$. A HP-5 MS (5\% phenyl methyl siloxane) capillary column was used as helium gas carrier at $1 \mathrm{~mL}$ every 1 minute. Heat was gradually applied until $40{ }^{\circ} \mathrm{C}$ was reached whilst keeping it constant for 10 minutes; then, increased by $3{ }^{\circ} \mathrm{C}$ every minute until peak temperature of $250{ }^{\circ} \mathrm{C}$ keeping it constant for 5 another minutes. MS was functioning at $70 \mathrm{eV}$. Individual compounds detected by GC-MS were matched with NIST 05 reference library.

\section{Statistical analysis}

Antioxidant tests were repeated three times and the result expressed in means \pm standard deviation (SD). Statistical analysis of antioxidant result was computed using Statistical Package for the Social Sciences software (SPSS) and included using one-way analysis of variance (ANOVA) whilst Tukey's post hoc determined the statistical significance at $p$-value $<0.05$. In order to correlate the antioxidant activity to phenolic content in methanolic extract, a Pearson's correlation in SPSS software was performed.

\section{Results}

\section{Genomic and phylogenetic analysis of Streptomyces sp. strain MUSC 5}

The 1489 bp $16 \mathrm{~S}$ rRNA sequence of Streptomyces sp. strain MUSC 5 (GenBank accession number KP998433) from its gDNA enabled retrieving representative of closely related taxa and manually aligned. The phylogenetic tree of Streptomyces sp. strain MUSC 5 is depicted in Figure 1. The phylogenetic tree constructed showed strain MUSC 5 forming sister clade with Streptomyces drozdowiczii NBRC $101007^{\mathrm{T}}$ at bootstrap value of $63 \%$. Closest representation of taxa was established between Streptomyces drozdowiczii NBRC101007 ${ }^{\mathrm{T}}(99.52 \%)$ followed by Streptomyces laculatispora BK166 ${ }^{\mathrm{T}} \quad(99.37 \%)$ and Streptomyces brevispora $\mathrm{BK} 160^{\mathrm{T}}(99.30 \%)$. 


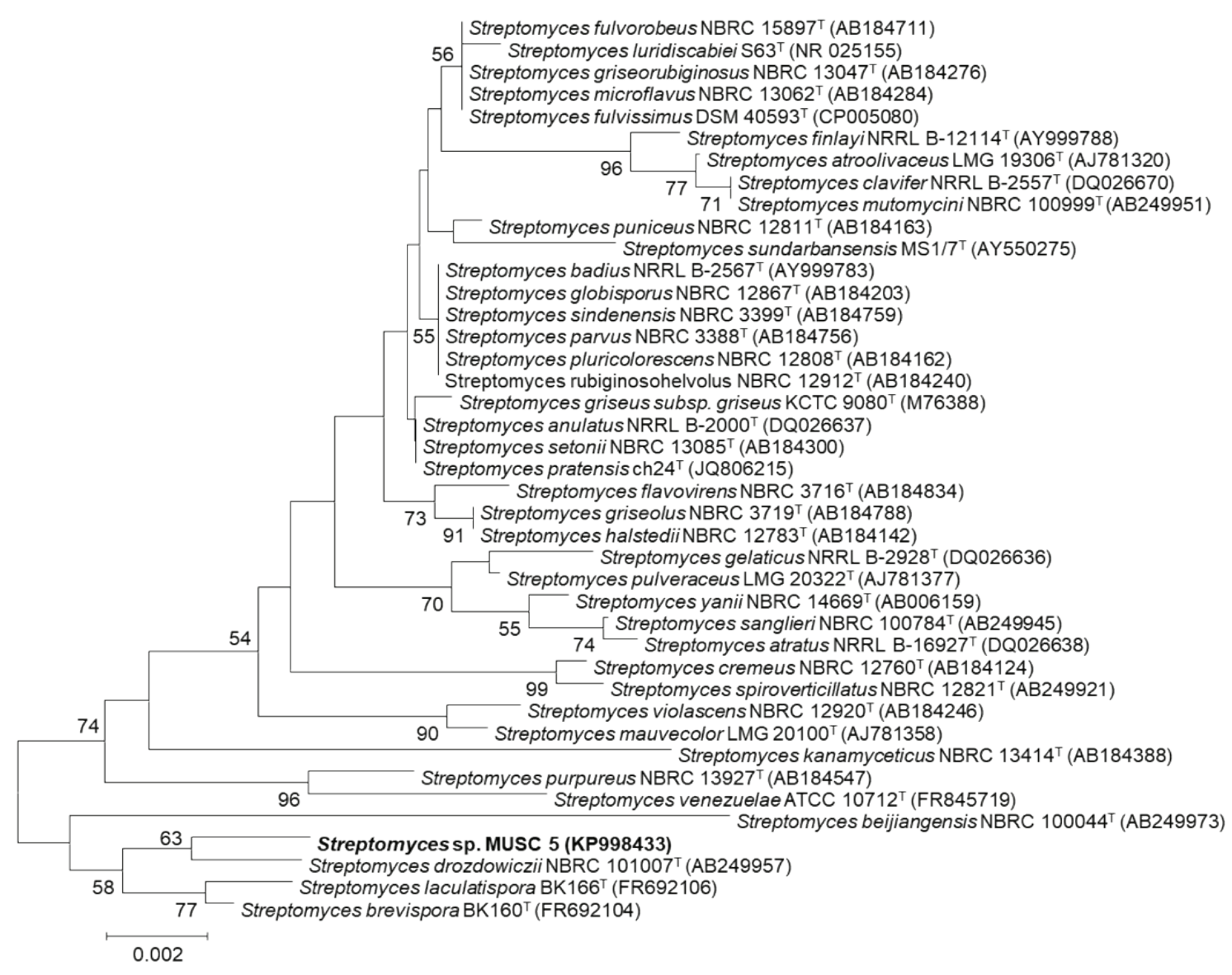

Figure 1. Neighbour-joining phylogenetic tree based on 1489 nucleotides of $16 \mathrm{~S}$ rRNA gene sequence showing the relationship between strain MUSC 5 and closely related member strains. Numbers and nodes indicate percentages (> $50 \%$ ) of 1000 bootstrap re-sampling. Bar, 0.002 substitutions per site.

\section{Cultural characterization, physiological tolerance and biochemical characterization}

The growth of Streptomyces sp. strain MUSC 5 on various media is shown in Table 1 . Streptomyces sp. strain MUSC 5 grew abundantly on ISP 2, ISP5, ISP6, ISP7 and SCA and SA after 7-14 days at $28^{\circ} \mathrm{C}$. This is in agreement by Gottlieb and Shirling who recommend ISP media for the growth of Streptomyces ${ }^{[67]}$. Colour of colony of mycelia were noted on all media grown, except ISP4. A light greyish olive and dark yellow pigments were visible on ISP 6 and NA, respectively (Table 1). Optimal conditions for growth were temperature of $26^{\circ} \mathrm{C}, \mathrm{pH}$ of 6-7 and salinity concentration of $2 \% \mathrm{w} / \mathrm{v}$. Streptomyces sp. strain MUSC 5 was tested positive for catalase. Results of the biochemical analysis suggested the production of catalase, xylanase and cellulase and amylase by Streptomyces sp. strain MUSC 5 (Table 2).

Table 1. Cultural characteristics of Streptomyces sp. strain MUSC 5.

\begin{tabular}{|c|c|c|c|c|}
\hline \multirow[t]{2}{*}{ Media } & \multirow[t]{2}{*}{ Growth } & \multicolumn{2}{|c|}{ Colony colour } & \multirow[t]{2}{*}{ Soluble pigments } \\
\hline & & Aerial mycelia & Substrate mycelia & \\
\hline ISP 2 & Well & $\begin{array}{c}\text { Brilliant Greenish } \\
\text { Yellow }\end{array}$ & Vivid Yellow & - \\
\hline ISP 3 & Poor & Light Olive Grey & Moderate Olive & - \\
\hline ISP 4 & - & - & - & - \\
\hline ISP 5 & Well & Dark Greyish Yellow & Light Yellowish Brown & - \\
\hline ISP 6 & Well & Pale Yellow & Moderate Yellow & Light greyish olive \\
\hline ISP 7 & Well & Light Olive Grey & Light Greyish Olive & - \\
\hline AIA & Moderate & $\begin{array}{l}\text { Pale Greenish Yel- } \\
\text { low }\end{array}$ & Pale Greenish Yellow & - \\
\hline SCA & Well & Medium Grey & Light Greyish Olive & - \\
\hline SA & Well & Light Orange Yellow & Brilliant yellow & - \\
\hline NA & Moderate & Yellowish Grey & Light Greyish Yellow Brown & Dark yellow \\
\hline
\end{tabular}

- No growth on ISP 4 and no production of soluble pigment 
Table 2. Biochemical and physiological characteristics of Streptomyces sp. strain MUSC 5.

\begin{tabular}{ll}
\hline Catalase & + \\
Haemolytic & - \\
\hline Enzymatic test & - \\
\hline Chitinase activity $(2.5 \%$ chitin $)$ & + \\
Xylanase activity $(0.5 \%$ xylan $)$ & $++)$ \\
Amylolytic activity $(0.2 \%$ starch $)$ & - \\
Protease activity $(2 \%$ casein $)$ & - \\
Lipase activity $(1 \%$ tributyrin $)$ & + \\
Cellulase activity $(0.5 \%$ CMC) & \\
\hline Temperature $\left({ }^{\circ} \mathbf{C}\right)$ & $26-37$ \\
\hline Growth & 26 \\
Optimum & \\
\hline NaCl (\%) tolerance & $0-6$ \\
\hline Growth & 2 \\
Optimum & $6-8$ \\
\hline pH tolerance & $6-7$ \\
\hline Growth & \\
Optimum & \\
\hline
\end{tabular}

- No activity; ${ }^{+}$activity; ${ }^{(+)}$weak activity

\section{ABTS radical scavenging assay}

Scavenging of ABTS radical by the methanolic extract was assessed by reacting ABTS radical cation with methanolic extract and thereafter observing visible colour change from blue-green to colourless. The colour change is suggestive of ABTS scavenging activity. The UV absorbance of free ABTS radical was taken at $743 \mathrm{~nm}$ with result showing a concentration dependent scavenging of ABTS radical $(p<0.05)$ with $24.97 \pm 0.99 \%$ as the highest activity measured at $4 \mathrm{mg} / \mathrm{mL}$ (Table 3).

\section{DPPH radical scavenging assay}

Scavenging of DPPH radical by methanolic extract was assessed based on the visible colour change from purple (DPPH radical) to yellow (diphenylpicrylhydrazine) in the reaction mixture. Quantitative analysis of this antioxidant activity was based on the UV absorbance reading taken at $515 \mathrm{~nm}$ which is the wavelength that detects free DPPH radical. The result of this experiment demonstrated the DPPH radical scavenging potential of methanolic extract MUSC 5 with an activity (p $<0.05)$ of $22.95 \pm 3.21 \%$ at its highest concentration of 4 $\mathrm{mg} / \mathrm{mL}$ (Table 3).

\section{Metal chelating assay}

In this experiment, the ferrozine reagent was used to assess the ferrous ion $\left(\mathrm{Fe}^{2+}\right)$ chelating ability of methanolic extract. The metal chelating potential of the methanolic extract was thereafter evaluated by taking the absorbance of complex of $\mathrm{Fe}^{2+}$-ferrozine at $562 \mathrm{~nm}$. A low absorbance reading normally suggests that most of the ferrous iron have been prevented to form complex with ferrozine by the metabolites within the methanolic extract. The result of this study indicated that methanolic extract had a metal chelating activity $(\mathrm{p}<0.05)$ of $26.81 \pm 1.05 \%$ at $4 \mathrm{mg} / \mathrm{mL}$ (Table 3 ).

Table 3. Scavenging of free radicals and chelation of metal ion by methanolic extract.

\begin{tabular}{cccc}
\hline Concentration $(\mathbf{m g} / \mathbf{m L})$ & \multicolumn{3}{c}{ Antioxidant activities (\%) } \\
\cline { 2 - 4 } & & DPPH radical scavenging activity & Metal chelating activity \\
\hline 0.125 & $3.04 \pm 0.54^{*}$ & $2.11 \pm 4.92$ & $3.05 \pm 2.43$ \\
0.25 & $4.65 \pm 0.95^{*}$ & $2.08 \pm 4.73$ & $4.13 \pm 1.81^{*}$ \\
0.5 & $4.61 \pm 1.14^{*}$ & $4.35 \pm 6.12$ & $4.97 \pm 0.65^{*}$ \\
1 & $6.00 \pm 1.15^{*}$ & $6.15 \pm 6.73$ & $8.60 \pm 1.78^{*}$ \\
2 & $14.55 \pm 0.68^{*}$ & $16.39 \pm 5.69^{*}$ & $12.94 \pm 2.13^{*}$ \\
\hline Gallic acid $^{\mathrm{a}}$ & $24.97 \pm 0.99^{*}$ & $22.95 \pm 3.21^{*}$ & $26.81 \pm 1.05^{*}$ \\
Gallic acid $^{\mathrm{b}}$ & $42.50 \pm 0.60^{*}$ & - & - \\
EDTA $^{\mathrm{c}}$ & - & $53.99 \pm 4.06^{*}$ & - \\
SStical scavenging activity $^{4}$ & - & - & $68.49 \pm 7.68^{*}$ \\
\hline
\end{tabular}

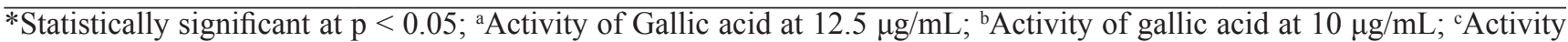
of EDTA at $0.125 \mathrm{mg} / \mathrm{mL}$ 


\section{FRAP assay}

Reduction potential of ferric ion to $\mathrm{Fe}^{2+}$ form by methanolic extract was assessed through FRAP assay. The amount of $\mathrm{Fe}^{2+}-\mathrm{Fe}^{3+}$ complex formed was measured with UV wavelength light absorbance of $700 \mathrm{~nm}$. Given there is activity, the colour of the reaction mixture changes to Prussian blue and indicates the methanolic extract has reducing power. The result showed that methanolic extract absorbance was $0.77-0.85$, in the dose range of 1-2 $\mathrm{mg}$ (Figure 2) which was equivalent to $1.73-2.15 \mu \mathrm{g}$ of ascorbic acid.

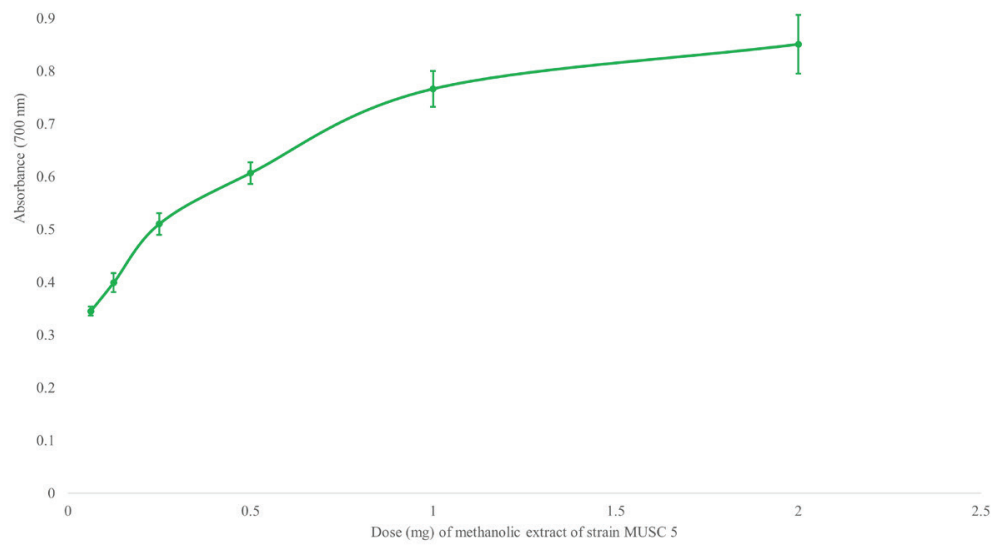

Figure 2. FRAP of the methanolic extract of Streptomyces sp. MUSC 5. The 6 doses $(0.0625 \mathrm{mg}, 0.125 \mathrm{mg} .0 .25 \mathrm{mg}, 0.5 \mathrm{mg}, 1 \mathrm{mg}$ and $2 \mathrm{mg})$ represents the 6 test concentrations employed $(2.5 \mathrm{mg} / \mathrm{mL}, 5 \mathrm{mg} / \mathrm{mL}, 10 \mathrm{mg} / \mathrm{mL}, 20 \mathrm{mg} / \mathrm{mL}, 40 \mathrm{mg} / \mathrm{mL}$ and $80 \mathrm{mg} / \mathrm{mL})$. Values are based on experiment run in triplicates \pm standard deviation.

\section{GC-MS Chemical profiling of methanolic extract of Streptomyces sp. MUSC 5}

Chemical profiling of various constituents was achieved by the use of the GC-MS together with the mass spectral data provided by the NIST library. From this, 11 compounds identified belonged to the class of pyrrolopyrazine, esters, fatty acid esters, triterpene and an alkane. Further information regarding individual compounds are provided in Table 4 and Figure 3.

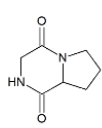

(1)

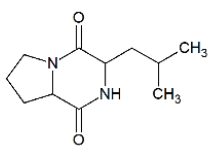

(2)<smiles>CCCCCCCCCCCCCCCCCCCCCCC(=O)OC</smiles>

(3)

(4)
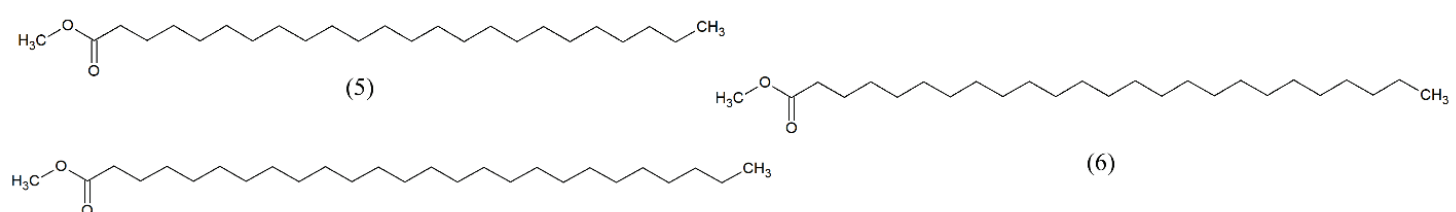

(6)

(7)

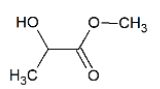

(9)

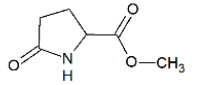

$(10)$

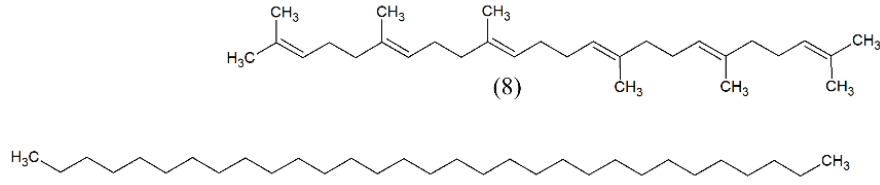

(11)

Figure 3. The molecular structures of the chemical compounds detected by GC-MS in the methanolic extract of Streptomyces sp. strain MUSC 5 .

Table 4. Compounds detected by GC-MS.

\begin{tabular}{|c|c|c|c|c|c|}
\hline No. & Constituents & Retention time ( $\mathrm{min})$ & Molecular Formula & Molecular weight & Similarity $(\%)$ \\
\hline 1 & Pyrrolo[1,2-a]pyrazine-1,4-dione, hexahydro- & 53.752 & $\mathrm{C}_{7} \mathrm{H}_{10} \mathrm{~N}_{2} \mathrm{O}_{2}$ & 154 & 94 \\
\hline 2 & Pyrrolo[1,2-a]pyrazine-1,4-dione, hexahydro-3-(2-methylpropyl)- & 55.048 & $\mathrm{C}_{11} \mathrm{H}_{18} \mathrm{~N}_{2} \mathrm{O}_{2}$ & 210 & 81 \\
\hline 3 & Tricosanoic acid, methyl ester & 58.797 & $\mathrm{C}_{24} \mathrm{H}_{48} \mathrm{O}_{2}$ & 368 & 80 \\
\hline 4 & Triacontanoic acid, methyl ester & 63.184 & $\mathrm{C}_{31} \mathrm{H}_{62} \mathrm{O}_{2}$ & 466 & 86 \\
\hline 5 & Tetracosanoic acid, methyl ester & 65.669 & $\mathrm{C}_{25} \mathrm{H}_{50} \mathrm{O}_{2}$ & 382 & 93 \\
\hline 6 & Pentacosanoic acid, methyl ester & 77.07 & $\mathrm{C}_{26} \mathrm{H}_{52} \mathrm{O}_{2}$ & 396 & 93 \\
\hline 7 & Hexacosanoic acid, methyl ester & 81.538 & $\mathrm{C}_{27} \mathrm{H}_{54} \mathrm{O}_{2}$ & 410 & 93 \\
\hline 8 & Squalene & 76.578 & $\mathrm{C}_{30} \mathrm{H}_{50}$ & 410 & 95 \\
\hline 9 & Propanoic acid, 2-hydroxy-, methyl ester & 3.852 & $\mathrm{C}_{4} \mathrm{H}_{8} \mathrm{O}_{3}$ & 104 & 99 \\
\hline 10 & DL-Proline, 5-oxo-, methyl ester & 38.665 & $\mathrm{C}_{6} \mathrm{H}_{9} \mathrm{NO}_{3}$ & 143 & 96 \\
\hline 11 & Hentriacontane & 79.802 & $\mathrm{C}_{31} \mathrm{H}_{64}$ & 436 & 96 \\
\hline
\end{tabular}




\section{Discussion}

The 16S rRNA is widely recognised as the golden standard for identification of bacteria at the genus leve ${ }^{[77]}$ and was therefore applied to validate that the strain belonged to the Streptomyces genus ${ }^{[12]}$. Having acquired the 16S rRNA gene sequence of Streptomyces sp. strain MUSC 5 with a 1489 bp, assisted with the construction of phylogenetic tree (Figure 1). Analysis of the tree placed the strain MUSC 5 within the Streptomyces genus. Apart from conferring the status of Streptomyces to the strain MUSC 5, close relations were also investigated revealing Streptomyces drozdowiczii NRBC $101007^{\mathrm{T}}$ at bootstrap value of 63 $\%$. Closest relation was established with Streptomyces drozdowiczii NBRC101007 ${ }^{\mathrm{T}}(99.52 \%)$ followed by Streptomyces laculatispora BK166 ${ }^{\mathrm{T}}(99.37 \%)$ and Streptomyces brevispora BK160 ${ }^{\mathrm{T}}$ (99.3\%). Further information regarding the physical, physiological and biochemical characteristics of Streptomyces sp. strain MUSC 5 was also conducted in the current study to provide phenotypic characterization and could be also useful for other research purposes. The strain was able to utilize a wide range of nutrients, produce soluble pigment and coloured colony, as shown by the result presented in Table 1. The strain showed potential in producing extracellular enzymes as well as tolerating different temperatures, salinity and $\mathrm{pH}$ (Table 1).

The methanolic extract was evaluated for antioxidant potential utilized a combination of radical scavenging assays and reduction power of antioxidants. The radical scavenging assays was chosen on the basis of its sensitivity and ease of performance and thus the use of ABTS and DPPH ${ }^{[78]}$. Herein, we report the radical scavenging activity of methanolic extract as having an ABTS and DPPH activity of $24.97 \pm 0.99 \%$ and 22.95 $\pm 3.21 \%$, respectively, at $4 \mathrm{mg} / \mathrm{mL}$ (Table 3 ).

The metal chelation antioxidant assay was carried out to examine the potential of the methanolic extract to interfere with the formation of coloured complex between ferrozine with ferrous ion ${ }^{[41]}$. In the biological system, $\mathrm{Fe}^{2+}$ is involved as a catalyst in the formation of hydroxyl radical $\left(\mathrm{OH}^{\bullet}\right)$ through the Fenton reaction ${ }^{[79]}$. The $\mathrm{OH}^{\bullet} \bullet^{-}$are the most destructive of all ROS, and removing it from the system is critical for maintaining homeostasis. The use of antioxidants that are capable to terminate hydroxyl radicals by chelating with ferrous ion would proof worthwhile. The result of the metal chelating test show that methanolic extract had a moderate activity $(\mathrm{p}<0.05)$ of $26.81 \pm 1.05 \%$ at $4 \mathrm{mg} / \mathrm{mL}$ (Table 3 ).

FRAP is an antioxidant assay that measures a different aspect of ROS by process known as dismutation. In this experiment, both the oxidation and reduction happen concurrently involving an exchange of electrons between a reductant and an oxidant ${ }^{[80]}$. Here, the methanolic extract and ferrocyanide undergo dismutation. Given that methanolic extract possess antioxidant potential, it will exchange its electron with ferrocyanide and become oxidised. The ferricyanide is transformed to ferrocyanide and later reacted with ferric chloride forming $\mathrm{Fe}^{2+}-\mathrm{Fe}^{3+}$ complex which has an absorb UV-Vis light at 700nm. In this experiment, the FRAP value was found within the dose range of 1-2 mg (Figure 2). This was equivalent of $1.73-2.15 \mu \mathrm{g}$ of ascorbic acid.

Given that methanolic extract demonstrated antioxidant activity, these findings have prompted further investigation into identification of the antioxidative compounds. The GCMS has become an common tool for chemical profiling of bioactive compounds after determining their biological activities $^{[81]}$. For this reason, GC-MS was used in the present study to detect chemical constituents in the methanolic extract MUSC 5 (Table 4 and Figure 3). The GC-MS analysis led to the detection of 11 known compounds, including Pyrrolo[1,2-a]pyrazine-1,4-dione, hexahydro(1), Pyrrolo[1,2-a]pyrazine-1,4-dione, hexahydro-3(2-methylpropyl)- (2), Tricosanoic acid, methyl ester (3), Triacontanoic acid, methyl ester (4), Tetracosanoic acid, methyl ester (5), Pentacosanoic acid, methyl ester (6), Hexacosanoic acid, methyl ester (7), Squalene (8), Propanoic acid, 2-hydroxy-, methyl ester (9), DL-Proline, 5-oxo-, methyl ester (10) and Hentriacontane (11).

Pyrrolopyrazines exist as a class of heterocyclic compounds frequently recovered from microbial extracts. For example, compound (1) isolated from a Bacillus strain was identified as the active compound with strong DPPH radical scavenging activity as well as exhibiting activity against multi-drug resistant Staphylococcus aureus ${ }^{[82]}$.Compound (2) among the 3 constituents present in ethyl acetate extract was identified in a marine Streptomyces sp. S2A as the major constituent responsible for the antioxidant activities (DPPH, ABTS, metal chelating and FRAP), antibacterial, enzyme inhibitory and cytotoxic effects ${ }^{[83]}$.

In addition to the two pyrrolopyrazine compounds, several of the fatty acid esters were also detected by GC-MS in the current study. In the current study, GC-MS detected 5 fatty acid methyl esters (3-7) in the methanolic extract of Streptomyces sp. strain MUSC 5. Compound (3) has been previously detected by GC-MS in microbes ${ }^{[84]}$. Triacontanoic acid, methyl ester (4) present in a plant extract showed anticancer property ${ }^{[85]}$. Another plant extract displaying antidiabetic activity was found to contain tetracosanoic acid, methyl ester, $(5)^{[86]}$. Both the ethanolic and water extract of propolis demonstrated antioxidant and antimicrobial activities and pentacosanoic acid, methyl ester (6) was confirmed in both extracts ${ }^{[87]}$. Hexacosanoic acid, methyl ester (7) was reported in a plant extract demonstrating anticancer properties ${ }^{[88]}$.

Interestingly, GC-MS detected squalene (8), a biologically active triterpene, which was first reported from a shark liver oil by Tsujimoto $(1916)^{[89]}$. To date, shark liver oil has been the major source of squalene, although this compound is also naturally produced in minute quantity by Streptomyces. For instance, Streptomyces sp. QC45B was shown to synthesize squalene via the methylerythritol phosphate pathway (MEP) [90].

Other miscellaneous compounds detected by GC-MS in the current study include propanoic acid, 2-hydroxy-, methyl ester (9) commonly known as methyl lactate. It is a volatile oil produced by plants and was detected by GC-MS in studies investigating the chemical composition of coffee 
beans $^{[91]}$. Compound (10) was detected in methanolic extract of Bacillus sp. strain SB1 and Halobacillus sp. strain SB2 having demonstrated antioxidant activity ${ }^{[92]}$. A long chain alkane hentriacontane (11) in a plant extract displayed biological activities including, antimicrobial and antioxidant activity ${ }^{[93]}$.

\section{Conclusion}

The methanolic extract of Streptomyces sp. strain MUSC 5 has demonstrated antioxidant activity by radical scavenging and FRAP assays. Furthermore, GC-MS analysis detected the presence of 11 compounds in the methanolic extract having a variety of known biological activity. This study adds support to the notion that understudied mangrove forest in Malaysia hold promising Streptomyces with antioxidant metabolites that could be resourceful in the development of safer antioxidant agents in addressing oxidative stress which has been associated with several medical conditions.

\section{Author Contributions}

K-HM, LT-HT and B-HG executed the experiments, analysed data and participated in the writing of the manuscript. Additional technical supports and proofreading were provided by LT-HT, H-LS, JW-FL. $\mathrm{B}-\mathrm{HG}, \mathrm{K}-\mathrm{GC}$ also provided funding of the project. B-HG developed the research project.

\section{Conflict of Interest}

The authors hereby declare no competing interest.

\section{Acknowledgements}

This work was inspired by Monash PhD Research Training Module which entitled "Bioprospective of microbes with biopharmaceutical potential with bioinformatics and drug discovery platforms" and financially by University Malaya Research Grant (PPP grants PG136-2016A and PG135-2016A and JBK grant GA002-2016), Monash Global Asia in the 21st Century (GA21) research grant (GA-HW-19-L01 \& GA-HW-19-S01) and Fundamental Research Grant Scheme (FRGS/1/2019/WAB09/ MUSM/02/1 \& FRGS/1/2019/SKK08/MUSM/02/7).

\section{References}

1. Zhang $\mathrm{J}$ and Piantadosi CA, Mitochondrial oxidative stress after carbon monoxide hypoxia in the rat brain. J Clin Invest 1992; 90(4): $1193-1199$

2. Lin MT and Beal MF, Mitochondrial dysfunction and oxidative stress in neurodegenerative diseases. Nature 2006; 443(7113): 787.

3. Parohan M, Sadeghi A, Khatibi SR, et al., Dietary total antioxidant capacity and risk of cancer: a systematic review and meta-analysis on observational studies. Crit Rev Oncol Hematol 2019.

4. Kemung HM, Hern T, Loh T, et al., Streptomyces as a prominent resource of future anti-MRSA drugs. Front Microbiol 2018; 9: 2221
5. Patridge E, Gareiss P, Kinch MS, et al., An analysis of FDA-approved drugs: natural products and their derivatives. Drug Discov Today 2016; 21(2): 204-207.

6. Ser H-L, Law JW-F, Chaiyakunapruk N, et al., Fermentation conditions that affect clavulanic acid production in Streptomyces clavuligerus: A systematic review. Front Microbiol 2016; 7: 522

7. Azman A-S, Othman I, S Velu S, et al., Mangrove rare actinobacteria: taxonomy, natural compound, and discovery of bioactivity. Front Microbiol 2015; 6: 856

8. Law JW-F, Ser H-L, Khan TM, et al., The potential of Streptomyces as biocontrol agents against the rice blast fungus, Magnaporthe oryzae (Pyricularia oryzae). Front Microbiol 2017; 8: 3

9. Lee L-H, Chan K-G, Stach J, et al., The search for biological active agent (s) from actinobacteria. Front Microbiol 2018; 9: 824

10. Azman A-S, Othman I, Fang C-M, et al., Antibacterial, anticancer and neuroprotective activities of rare Actinobacteria from mangrove fores soils. Indian J Microbiol 2017; 57(2): 177-187.

11. Waksman SA and Henrici AT, The nomenclature and classification of the actinomycetes. J Bacteriol 1943; 46(4): 337.

12. Law JW-F, Tan K-X, Wong SH, et al., Taxonomic and characterization methods of Streptomyces: a review. Prog Microbes Mol Biol 2018; $1(1)$.

13. Bruce T, Martinez IB, Neto OM, et al., Bacterial community diversity in the Brazilian Atlantic forest soils. Microb Ecol 2010; 60(4): 840849 .

14. Jones D, Magthab E, Gleeson D, et al., Microbial competition for nitrogen and carbon is as intense in the subsoil as in the topsoil. Soil Biol Biochem 2018; 117: 72-82

15. Bentley SD, Chater KF, Cerdeño-Tárraga A-M, et al., Complete genome sequence of the model actinomycete Streptomyces coelicolor A3 (2). Nature 2002; 417(6885): 141

16. Ser H-L, Law JW-F, Tan W-S, et al., Genome sequence of bioactive streptomycete isolated from mangrove forest in East Malaysia, Streptomyces monashensis MUSC 1JT. Prog Drug Discov Biomed Sci 2019; 2(1).

17. Ser H-L, Tan W-S, Mutalib N-SA, et al., Genome sequence of Streptomyces gilvigriseus MUSC 26T isolated from mangrove forest. Braz J Microbiol 2018; 49(2): 207-209.

18. Ser H-L, Tan W-S, Yin W-F, et al., Whole genome sequence of Streptomyces humi strain MUSC 119T isolated from intertidal soil Prog Drug Discov Biomed Sci 2019; 2(1).

19. Ser H-L, Tan W-S, Ab Mutalib N-S, et al., Draft genome sequence of mangrove-derived Streptomyces sp. MUSC 125 with antioxidan potential. Front Microbiol 2016; 7: 1470

20. Ser H-L, Tan W-S, Ab Mutalib N-S, et al, Genome sequence of Streptomyces mangrovisoli MUSC 149T isolated from intertidal sediments. Braz J Microbiol 2018; 49(1): 13-15.

21. Ser H-L, Tan W-S, Ab Mutalib N-S, et al., Genome sequence of Streptomyces pluripotens MUSC 135T exhibiting antibacterial and antioxidant activity. Mar Genomics 2015; 24: 281-283.

22. Tan LT-H, Chan K-G, Lee L-H, et al., Streptomyces bacteria as Tan LT-H, Chan K-G, Lee L-H, et al., Streptomyces bacteria
potential probiotics in aquaculture. Front Microbiol 2016; 7: 79.

23. Lee L-H, Law JW-F, Khan TM, et al., IDDF2019-ABS-0323 Unveiling the anti-colon cancer potential of sarawak mangrove-derived nove streptomycetes. 2019, BMJ Publishing Group.

24. Lee L-H, Ser H-L, Ab Mutalib N-S, et al., IDDF2018-ABS-0207 Winning the war against colon cancer: chemo-preventive potential of novel streptomyces species derived from mangrove forest in malaysia. 2018, BMJ Publishing Group.

25. Tan LT-H, Chan C-K, Chan K-G, et al., Streptomyces sp. MUM256: A source for apoptosis inducing and cell cycle-arresting bioactive compounds against colon cancer cells. Cancers (Basel) 2019; 11(11) 1742.

26. Ser H-L, Zainal N, Palanisamy UD, et al., Streptomyces gilvigriseus sp. nov., a novel actinobacterium isolated from mangrove forest soil. Antonie Van Leeuwenhoek 2015; 107(6): 1369-1378.

27. de Lima Procópio RE, da Silva IR, Martins MK, et al., Antibiotics produced by Streptomyces. Braz J Infect Dis 2012; 16(5): 466-471.

28 Berdy J, Bioactive microbial metabolites. J Antibiot 2005; 58(1): 1

29. Tan LT-H, Lee L-H, and Goh B-H, The bioprospecting of anti-Vibrio Streptomyces species: Prevalence and applications. Prog Microbe Mol Biol 2019; 2(1)

30. Tan LT-H, Lee L-H, and Goh B-H, Critical review of fermentation and extraction of anti-Vibrio compounds from Streptomyces. Prog Microbes Mol Biol 2020; 3(1)

31. Ser H-L, Yin W-F, Chan K-G, et al., Antioxidant and cytotoxic potentials of Streptomyces gilvigriseus MUSC 26T isolated from mangrove soil in Malaysia. Prog Microbes Mol Biol 2018; 1(1).

32. Law JW-F, Letchumanan V, Tan LT-H, et al., The rising of "Modern Actinobacteria" era. Prog Microbes Mol Biol 2020; 3(1).

33. Law JW-F, Pusparajah P, Ab Mutalib N-S, et al., A review on mangrove actinobacterial diversity: the roles of Streptomyces and novel species discovery. Prog Microbes Mol Biol 2019; 1(1).

34. Lee L-H, Cheah Y-K, Sidik SM, et al., Molecular characterization of Antarctic actinobacteria and screening for antimicrobial metabolite production. World J Microb Biot 2012; 28(5): 2125-2137.

35. Rani R, Arora S, Kaur J, et al., Phenolic compounds as antioxidants and chemopreventive drugs from Streptomyces cellulosae strain TES17 isolated from rhizosphere of Camellia sinensis. BMC Complement Altern Med 2018; 18(1): 82

36. Kemung HM, Tan LT-H, Chan K-G, et al., Investigating the antioxidant potential of Streptomyces sp. MUSC 11 from mangrove soil in Malaysia. Prog Drug Discov Biomed Sci 2019; 2(1).

37. Kemung HM, Tan LT-H, Chan K-G, et al., Antioxidant activities of 
Streptomyces sp. strain MUSC 14 from mangrove forest soil in Malaysia. BioMed Res Int 2020; 2020.

38. Ser H-L, Tan LT-H, Palanisamy UD et al., Streptomyces antioxidans sp. nov., a novel mangrove soil actinobacterium with antioxidative and neuroprotective potentials. Front Microbiol 2016; 7: 899.

39. Tan LTH, Mahendra CK, Yow YY, et al., Streptomyces sp. MUM273b: A mangrove $\square$ derived potential source for antioxidant and UVB radiation protectants. MicrobiologyOpen 2019: e859.

40. Tan LT-H, Chan K-G, Chan CK, et al., Antioxidative potential of a Streptomyces sp. MUM292 isolated from mangrove soil. BioMed Res Int 2018; 2018.

41. Tan LT-H, Chan K-G, Khan TM, et al., Streptomyces sp. MUM212 as a source of antioxidants with radical scavenging and metal chelating properties. Front Pharmacol 2017; 8: 276.

42. Tan LT-H, Chan K-G, Pusparajah P, et al., Mangrove derived Streptomyces sp. MUM265 as a potential source of antioxidant and anticolon-cancer agents. BMC Microbiol 2019; 19(1): 38.

43. Tan LT-H, Ser H-L, Yin W-F, et al., Investigation of antioxidative and anticancer potentials of Streptomyces sp. MUM256 isolated from Malaysia mangrove soil. Front Microbiol 2015; 6: 1316.

44. Law JW-F, Ser H-L, Ab Mutalib N-S, et al., Streptomyces monashensis sp. nov., a novel mangrove soil actinobacterium from East Malaysia with antioxidative potential. Sci Rep 2019; 9(1): 3056.

45. Law JW-F, Ser H-L, Duangjai A, et al., Streptomyces colonosanans sp. nov., a novel actinobacterium isolated from Malaysia mangrove soil exhibiting antioxidative activity and cytotoxic potential against human colon cancer cell lines. Front Microbiol 2017; 8: 877

46. Ser H-L, Palanisamy UD, Yin W-F, et al., Streptomyces malaysiense sp. nov.: A novel Malaysian mangrove soi actinobacterium with antioxidative activity and cytotoxic potential against human cancer cell lines. Sci Rep 2016; 6(1): $1-12$.

47. Ser H-L, Palanisamy UD, Yin W-F, et al., Presence of antioxidative agent, Pyrrolo [1, 2-a] pyrazine-1, 4-dione, hexahydro-in newly isolated Streptomyces mangrovisoli $\mathrm{sp}$. nov. Front Microbiol 2015; 6: 854

48. Ser H-L, Tan LT-H, Law JW-F, et al., Focused review: Cytotoxic and antioxidant potentials of mangrove-derived Streptomyces Front Microbiol 2017; 8: 2065

49. Ser H-L, Ab Mutalib N-S, Yin W-F, et al., Evaluation of antioxidative and cytotoxic activities of Streptomyces pluripotens MUSC 137 isolated from mangrove soil in Malaysia. Front Microbiol 2015; 6: 1398

50. Law JW-F, Chan K-G, He Y-W, et al., Diversity of Streptomyces spp. from mangrove forest of Sarawak (Malaysia) and screening of their antioxidant and cytotoxic activities. Sci Rep 2019; 9(1): $1-15$

51. Giri C, Ochieng E, Tieszen LL, et al., Status and distribution of mangrove forests of the world using earth observation satellite data. Global Ecol Biogeogr 2011; 20(1): 154-159.

52. Mendes LW and Tsai SM, Distinct taxonomic and functional composition of soil microbiomes along the gradient forestrestinga-mangrove in southeastern Brazil. Antonie Van Leeuwenhoek 2018; 111(1): 101-114.

53. Ser H-L, Ab Mutalib N-S, Yin W-F, et al., Genome sequence of Streptomyces antioxidans MUSC 164T isolated from mangrove forest. Prog Microbes Mol Biol 2018; 1(1).

54. Ser H-L, Chan K-G, Tan W-S, et al., Complete genome of mangrove-derived anti-MRSA streptomycete, Streptomyces pluripotens MUSC 135T. Prog Microbes Mol Biol 2018; 1(1).

55. Ser H-L, Law JW-F, Tan W-S, et al., Whole genome sequence of Streptomyces colonosanans strain MUSC93 $\mathrm{J}^{\mathrm{T}}$ isolated from mangrove froest in Malaysia. Prog Microbes Mol Biol 2020; 3(1): a0000061.

56. Zainal N, Ser H-L, Yin W-F, et al., Streptomyces humi sp. nov., an actinobacterium isolated from soil of a mangrove forest Antonie Van Leeuwenhoek 2016; 109(3): 467-474

57. Shepherd MD, Kharel MK, Bosserman MA, et al., Laboratory maintenance of Streptomyces species. Curr Protoc Microbiol 2010: 10E-1.

58. Lee L-H, Zainal N, Azman A-S, et al., Diversity and antimicrobial activities of actinobacteria isolated from tropical mangrove sediments in Malaysia. Scientific World Journal 2014; 2014

59. Hong K, Gao A-H, Xie Q-Y, et al., Actinomycetes for marine drug discovery isolated from mangrove soils and plants in China. Mar Drugs 2009; 7(1): 24-44.

60. Lee L-H, Zainal N, Azman A-S, et al., Streptomyces pluripoten sp. nov., a bacteriocin-producing streptomycete that inhibits meticillin-resistant Staphylococcus aureus. Int J Syst Evol Microbiol 2014; 64(9): 3297-3306.

61. Thompson JD, Gibson TJ, Plewniak F, et al., The CLUSTAL X windows interface: flexible strategies for multiple sequence alignment aided by quality analysis tools. Nucleic Acids Res 1997; 25(24): 4876-4882

62. Kim O-S, Cho Y-J, Lee K, et al., Introducing EzTaxon-e: a prokaryotic 16S rRNA gene sequence database with phylotype that represent uncultured species. Int J Syst Evol Microbiol 2012; 62(3): 716-721.

63. Tamura K, Stecher G, Peterson D, et al., MEGA6: Molecular evolutionary genetics analysis version 6.0. Mol Biol Evol 2013; 30(12): 2725-2729.

64. Saitou N and Nei M, The neighbor-joining method: a new method for reconstructing phylogenetic trees. Mol Biol Evol 1987; 4(4): 406425.

65. Kimura M, A simple method for estimating evolutionary rates of base substitutions through comparative studies of nucleotide sequences. J Mol Evol 1980; 16(2): 111-120.

66. Felsenstein J, Confidence limits on phylogenies: an approach using the bootstrap. Evolution 1985; 39(4): 783-791.

67. Shirling ET and Gottlieb D, Methods for characterization of Streptomyces species. Int J Syst Evol Microbiol 1966; 16(3): 313340.

68. Atlas RM, Handbook of microbiological Media. First ed. 1993, Boca Raton, Florida: CRC Press, Inc. 455-462.

69. Mac Faddin JF, Biochemical tests for identification of medical bacteria. First ed. 1976: Williams \& Wilkins Co.

70. Atlas RM, Handbook of microbiological Media. Fourth ed. 2010, Boca Raton, Florida: CRC press, Inc.

71. Küster E and Williams ST, Selection of media for isolation of streptomycetes. Nature 1964; 202(4935): 928

72. Kelly KL, ISCC-NBC color-name charts illustrated with centroid colors. 1964, US Government Printing Office: Washington DC.

73. Lee L-H, Zainal N, Azman A-S, et al., Mumia flava gen. nov., sp. nov., an actinobacterium of the family Nocardioidaceae. Int J Syst Evol Microbiol 2014; 64(5): 1461-1467.

74. Carrillo PG, Mardaraz C, Pitta-Alvarez SI, et al., Isolation and selection of biosurfactant-producing bacteria. World J Microb Biot 1996; 12(1): 82-84

75. Meena B, Rajan LA, Vinithkumar NV, et al., Novel marine actinobacteria from emerald Andaman \& Nicobar Islands: A prospective source for industrial and pharmaceutical byproducts BMC Microbiol 2013; 13(1): 145.

76. Adjimani JP and Asare P, Antioxidant and free radical scavenging activity of iron chelators. Toxicol Rep 2015; 2: 721-728.

77. Clarridge JE, Impact of $16 \mathrm{~S}$ rRNA gene sequence analysis for identification of bacteria on clinical microbiology and infectious diseases. Clin Microbiol Rev 2004; 17(4): 840-862.

78. Moon J-K and Shibamoto T, Antioxidant assays for plant and food components. J Agric Food Chem 2009; 57(5): 1655-1666.

79. Fenton $\mathrm{HJH}$, Oxidation of tartaric acid in presence of iron. J Chem Soc, Trans 1894; 65: 899-910.

80. Benzie IF and Strain JJ, The ferric reducing ability of plasma (FRAP) as a measure of "Antioxidant Power": The FRAP Assay. Anal Biochem 1996; 239(1): 70-76.

81. Al-Dhabi NA, Esmail GA, Ghilan A-KM, et al., Chemical constituents of Streptomyces sp. strain Al-Dhabi-97 isolated from the marine region of Saudi Arabia with antibacterial and anticancer properties. J Infect Public Heal 2019

82. Kiran GS, Priyadharsini S, Sajayan A, et al., An antibiotic agent pyrrolo [1, 2-a] pyrazine-1, 4-dione, hexahydro isolated from a marine bacteria Bacillus tequilensis MSI45 effectively controls multidrug resistant Staphylococcus aureus. RSC Adv 2018; 8(32): 1783717846.

83. Siddharth $\mathrm{S}$ and Vittal R, Evaluation of antimicrobial, enzyme inhibitory, antioxidant and cytotoxic activities of partially purified volatile metabolites of marine Streptomyces $\mathrm{sp}$. S2A. Microorganisms 2018; 6(3): 72

84. Elbanhawy AA, Elsherbiny EA, El-Mageed AEA, et al., Potential of fungal metabolites as a biocontrol agent against cotton aphid, Aphis gossypii Glover and the possible mechanisms of action. Pestic Biochem Physiol 2019

85. Marzocco S, Formisano $\mathrm{C}$, Bruno $\mathrm{M}$, et al., Cytotoxic activity and composition of petroleum ether extract from Magydaris tomentosa (Desf.) WDJ Koch (Apiaceae). Molecules 2015; 20(1): 1571-1578.

86. Khan K, Rasheed M, Nadir M, et al., GC-MS \& preliminary screening profile of Cordia sinensis leaves-antiglycation, antifungal and insecticidal agents. Nat Prod Res 2019: 1-5

87. AL-Ani I, Zimmermann S, Reichling J, et al., Antimicrobial activities of European propolis collected from various geographic origins alone and in combination with antibiotics. Medicines 2018; 5(1): 2 .

88. Elias ST, Macedo CC, Simeoni LA, et al., Cytotoxic effect of Erythroxylum daphnites extract is associated with G1 cell cycle arrest and apoptosis in oral squamous cell carcinoma. Cell Cycle 2016; 15(7): 948-956.

89. Tsujimoto M, A highly unsaturated hydrocarbon in shark liver oil. Ind Eng Chem 1916; 8(10): 889-896.

90. Fontana A, Kelly MT, Prasad JD, et al., Evidence for the biosynthesis of squalene via the methylerythritol phosphate pathway in Streptomyces sp. obtained from a marine sediment. J Org Chem 2001; 66(18): 6202-6206

91. Sanz C, Maeztu L, Zapelena MJ, et al., Profiles of volatile compounds and sensory analysis of three blends of coffee: Influence of different proportions of Arabica and Robusta and influence of roasting coffee with sugar. J Sci Food Agric 2002; 82(8): 840-847.

92. Banik A, Pandya P, Patel B, et al., Characterization of halotolerant, pigmented, plant growth promoting bacteria of groundnut rhizosphere and its in-vitro evaluation of plant-microbe protocooperation to withstand salinity and metal stress. Sci Total Environ 2018; 630: 231-242.

93. Seraoui R, Benkiniouar R, Akkal S, et al., Phytochemical Investigation, Antioxidant and Antimicrobial Assays of Algerian Plant Calamintha baborensis Batt. Pharm Chem J 2018; 52(4): $347-$ 356. 